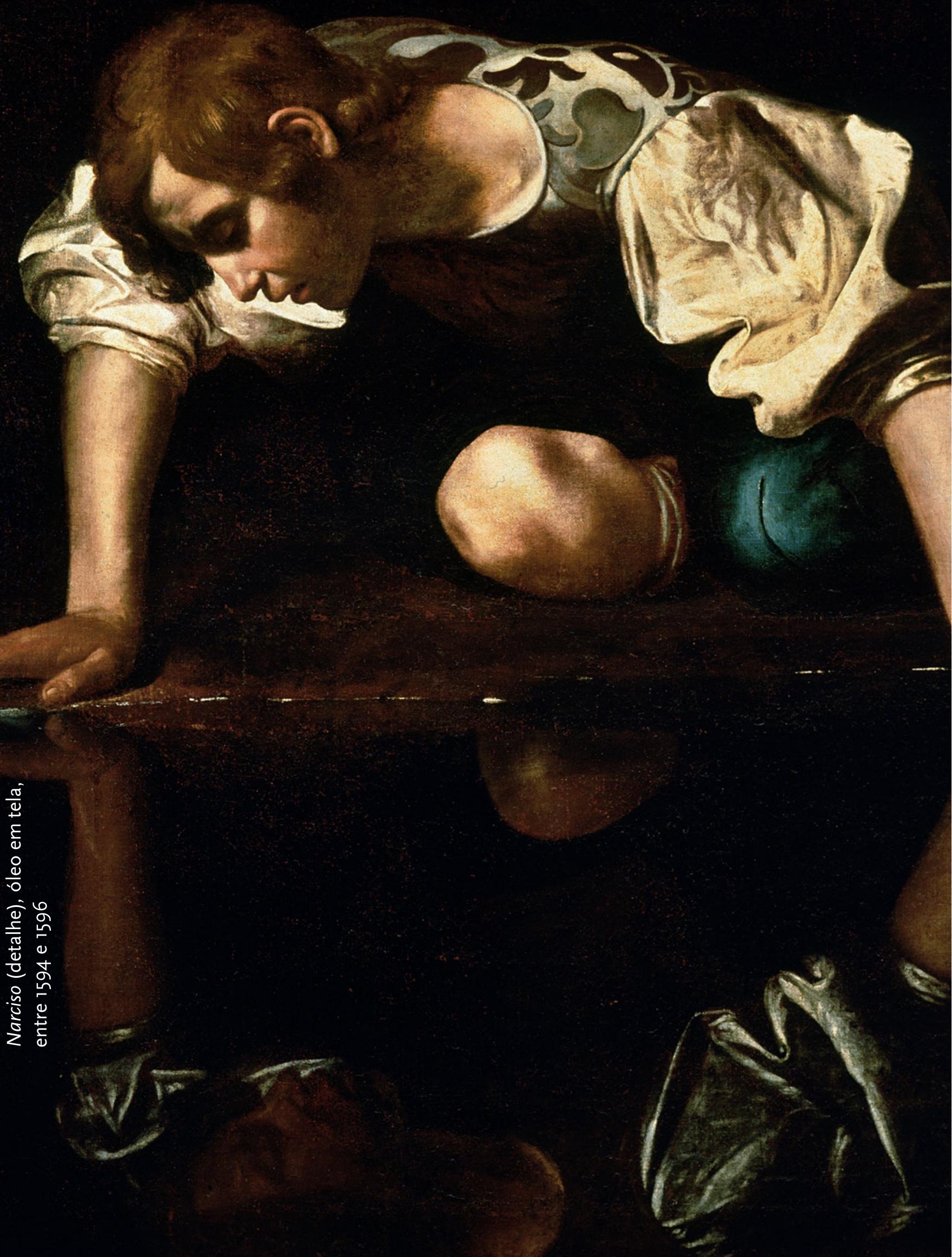




\section{A UTOPIA DA CURA EM PSICANÁLISE}

MARIA RITA KEHL*

RESUMO Se, por um lado, as utopias, criadas por nossa imaginação, são movidas pelo desejo, ainda que seja por um desejo não individual, mas coletivo, por outro lado, a sua realização seria a morte do desejo e, portanto, a efetivação das utopias seria uma realização totalitária. Diante desse problema, o artigo busca abordar a seguinte questão: seria a cura em psicanálise uma utopia? As possíveis respostas a essa questão são exploradas neste artigo tendo em vista a complexa relação entre utopia e desejo.

palavras-chave Utopia. Desejo. Cura. Psicanálise.

\section{THE UTOPIA OF THE CURE IN PSYCHOANALYSIS}

ABSTRACT If, on the one hand, the utopias created by our imagination are moved by desire, although not necessarily an individual but a collective desire, on the other hand, their realization would imply the death of desire and, therefore, the accomplishment of the utopias would be a totalitarian realization. Faced with this problem, the article seeks to answer the following question: would the cure in psychoanalysis be a utopia? The possible answers to this question are explored in this paper in view of the complex relationship between utopia and desire.

KeYwords Utopia. Desire. Cure. Psychoanalysis

* Psicanalista, escritora. Autora de, entre outros, "Deslocamentos do Feminino", tese de doutoramento pela PUC-SP

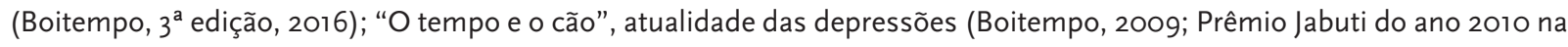
categoria de não ficção). Foi membro da Comissão Nacional da Verdade entre 2012 e 2014. 
Uma meta sempre tem que ter um alvo/ mas quando o poeta diz: meta/ deve estar querendo dizer o inatingível. (Gilberto Gil - Metáfora)

s utopias são produtos da nossa imaginação, movidos pela força do desejo. Por isso escolhi
como vinheta desta conferência a canção de Gilberto Gil, pois a utopia só nos interessa como meta inatingível. Do contrário, sua realização seria a morte do desejo.

Tentar partir do exercício da imaginação, em nome do desejo - ainda que seja um desejo coletivo - uma nova ordem social que procure igualar os ideais de satisfação e os modos de bem viver, para todos, pode ser o caminho mais certo para a consolidação de uma ordem totalitária. Os dois grandes regimes totalitários que envergonharam a civilização ocidental, no século XX, partiram de ideais utópicos. Não precisamos concordar com elas para admitir o caráter utópico, tanto da eugenia, ideal "científico" do aperfeiçoamento da raça, quanto da imposição de uma igualdade nivelada pelo Estado, na origem do stalinismo.

Por outro lado, não se pode viver sem alguma utopia que sustente nosso desejo de uma vida melhor, uma sociedade melhor, um mundo melhor - ainda no reino desse mundo (minha perspectiva é laica), pois o avesso da utopia talvez seja o cinismo: não acreditar em nada, não se comprometer com nenhum valor - para "tirar vantagem em tudo", como lembrou certa vez o 1 Ricardo Goldenberg: No psicanalista Ricardo Goldenberg ${ }^{\mathrm{I}}$. círculo cínico (2002).

A vida em sociedade é indissociável da condição humana. A identificação com o sofrimento do outro, antes de uma (boa) herança cristã, faz parte de uma sensibilidade atávica. O filhote de homem 2 TOURNIER, Michel: faz do outro seu espelho; humaniza-se por meio do outro. A bela fábula de Michel Tournier, SextaSexta-feira e os limbos do pacífico (1976). Tradução de Fernanda Botelho. São Paulo: Bertrand Brasil, 2011. feira ou os limbos do pacífico², sugere que, ao contrário do ideal colonizador presente na história inventada por Defoe 3 , o encontro com o selvagem Sexta-feira teria salvado o civilizado Robinson da completa desumanização. Longe do reconhecimento oferecido pelo olhar do outro, o sujeito Crusoé. Londres, 1719. se desumaniza.

Se o espelho do outro nos diz quem somos, é necessário reconhecer o preço pago por todos - até pelos ditos privilegiados - pelo mero fato da existência das desigualdades e da injustiça. $\mathrm{O}$ 
cinismo pode ser uma forma de defesa, como a arrogância e a indiferença; mas não impede que todos os que vivem em sociedades injustas sejam prejudicados em algum ponto de sua autoimagem ou de sua autoestima. Só por isso - por motivos que se podem chamar, em última instância, de egoístas - vale a pena levar em consideração o desejo utópico de igualdade social. Desde que se trate, evidentemente, da igualdade de condições. Condições iguais, justas e dignas para todos, de modo que cada um possa escolher o melhor destino para sua diferença.

Por essa razão, nossos desejos legítimos e progressistas de melhorar as condições da vida em sociedade (a única forma de vida humana que se conhece) podem indicar alvos que funcionem como atratores da ação política. Mas a realização dos ideais deve permanecer em aberto para não resultar em realizações totalitárias.

Nada mais opressivo do que uma utopia realizada - isso vale para todos os modelos, de Platão a Marx, passando por Thomas Morus e seu parodiador crítico, Aldous Huxley. O ser humano é imperfeito e, o que é mais complicado, seu comportamento e suas escolhas se regem por motivações inconscientes. Em decorrência disso, o laço social é instável e conflituoso. Na "menos pior" das hipóteses, a estabilidade da vida social depende da possibilidade de expressão dos conflitos - conflitos de interesse, de crença, de gosto, de escolhas de destino - assim como da consistência das soluções de compromisso inventadas e reinventadas, a cada vez.

Não é esse o tema que pretendo abordar aqui, mas vale lembrar, de passagem, que as utopias radicalmente individualistas da chamada sociedade de consumo, mesmo quando se aproximem da realização - como em algumas sociedades abastadas da América e da Europa - produzem sintomas de desilusão e depressão em massa, que nem mesmo o consumo de medicações psiquiátricas de última geração consegue curar. Se existe uma utopia radicalmente individualista, o melhor que posso dizer em relação a ela é que não me interessa.

Explico: o universo de mercadorias em que estamos inseridos há pelo menos três séculos - e com tanta naturalidade que já não somos capazes de sonhar com outra coisa - nos faz pensar que o desejo que move a vida humana deve ser necessariamente desejo de algo. O que seria esse "algo"? Existe, no infinito mundo dos bens e mercadorias produzidos hoje, algum objeto ou conjunto de objetos capazes de garantir a quem os possui um estado de plenitude, de felicidade, de bem-estar subjetivo, equivalentes 
à concretização de uma utopia - uma utopia consumista, por assim dizer? Se assim fosse, uma vez conquistada a coisa, deveria cessar o movimento do desejo? Na melhor das hipóteses, não. A saciedade definitiva do desejo pela obtenção de mercadorias seria a morte do sujeito, atolado em meio a objetos que ele acreditava serem a receita para a conquista de sua plenitude. Ou então, ao contrário - como temos observado na atualidade - o efeito dessa aposta seria depressão. Não há nada que se pareça mais com o estado depressivo do que uma plenitude constante. A plenitude é boa porque dura pouco. Quando se perpetua, quando o sujeito começa a viver como se já não desejasse mais nada, seu nome muda para: tédio, apatia, indiferença, saciedade - em suma: depressão. Mas notem que a relação entre saciedade e depressão ainda é uma hipótese otimista porque onde há sofrimento, há vida - e perspectiva de transformação.

Mas vale lembrar que até o indivíduo mais egoísta, mais antissocial, mais voltado apenas para seus interesses particulares participa do laço social. O “outro” está presente nele, desde sua constituição. Assim como todos nós, sua humanidade é tributária da sua identificação com o outro - ou com os outros. E mesmo aquele que se considera diferenciado, acima ou apartado de seus semelhantes, é obrigado a reconhecer que partilha com eles, no mínimo, a característica demasiado humana de viver em meio a símbolos e palavras. Além disso, mesmo que esse sujeito dito autossuficiente o ignore, suas escolhas supostamente “individuais” são sempre endereçadas a alguém.

Explico: o filhote de homem, à diferença de todos os outros animais, não nasce dotado do instinto, essa forma de saber que liga o animal ao meio ambiente do qual depende para sobreviver. Se o bezerro, ou o gatinho, procura instintivamente a teta da mãe, o bebê humano tem de ser apresentado a ela, quando não forçado às primeiras mamadas, para "aprender" que ali está o alimento que o sustenta. Nosso meio ambiente não é natural: é cultural. Portanto, simbólico. Já nas primeiras mamadas, nos primeiros cuidados, o filhote de homem é introduzido à cultura em que vivem seus pais. Ele depende, e por muito mais tempo que um bezerro ou um gatinho, da dedicação e do amor de seus genitores (ou algum substituto), ao passo que bezerros, gatinhos e outros, assim que aprendem a coordenar as próprias pernas, têm condições de buscar o alimento em seu habitat. A criança - cujo "habitat" é a cultura, portanto muito mais difícil de dominar - continua a depender da ajuda, dos ensinamentos, da proteção e, principalmente, do amor de seus pais durante muitos, muitos anos. 
Vocês poderiam perguntar: cuidado, proteção, ensinamentos, sim, são fundamentais para a sobrevivência do bebê. Amor é bom, claro. Mas por que seria tão imprescindível quanto os cuidados práticos e materiais? Por que um bebê bem alimentado, agasalhado e protegido por um adulto impessoal - um profissional de creche, por exemplo, que executasse todas as tarefas a contento, mas não se interessasse por crianças - não se desenvolveria tão bem quanto o outro, adorado por seus pais?

Ora, se nosso meio ambiente é cultural e não natural, se dependemos dos cuidados de alguém para sobreviver e do domínio da linguagem para nos situar no mundo, é fácil deduzir que todas essas circunstâncias nos tornam dependentes do amor de alguém. É preciso que alguém se interesse muito por nós, nos primeiros meses e anos de vida, para suportar toda a trabalheira que nossa prolongada dependência vai lhe dar. Mas o amor não garante apenas os bens necessários à sobrevivência física do bebê. O amor é o dom essencial para sua sobrevivência subjetiva, narcísica. Além do evidente prazer que a criança sente ao receber carinhos e ouvir vozes carinhosas de seus cuidadores, ela depende do olhar do outro (sobretudo da mãe e seus substitutos secundários) para, aos poucos, ter uma noção de que ela existe como ser independente, completo (no sentido dos atributos corporais) e dotado de valor. Se o amor e os carinhos do outro ajudam a criança a sentir, aos poucos, seu corpo como uma totalidade, o olhar do outro, sempre segundo Freud ${ }^{4}$, permite que a criança se identifique consigo mesma. Essas são as condições a que Freud chamou de "narcisismo primário", a primeira forma de amor do sujeito por si mesmo, desenvolvida nos primórdios da vida psíquica, quando ela ainda está diante dos outros, na expressão do autor, no lugar de “sua majestade, o bebê". Mais tarde, Lacan há de levar adiante as proposições freudianas sobre o narcisismo e desenvolver, em um texto fundamental chamado "O estádio do espelho e sua função na constituição do eu”, um complemento importante à teoria do narcisismo que não pretendo desenvolver aqui. Basta reter, desse texto, a ideia de que a criança percebe muito cedo (por volta dos I 8 meses de vida) a distância que separa sua imagem corporal "perfeita” (ou seja: completa, simétrica e tal) da percepção de insuficiência em relação ao domínio desse mesmo corpo. O “espelho" no qual a criança constata sua perfeição corporal não é apenas o pedaço de vidro onde ela eventualmente se reconhece pela primeira vez. Essa imagem só será percebida como completa se contar com a confirmação do olhar amoroso, maravilhado, que o outro também dirige
4 Ver Freud: "Introdução ao narcisismo" (1914).

5 Ver Lacan: "O estádio do espelho como constitutivo da função do eu" (1949). 
a ela. A triangulação criança-espelho-outro é fundamental para a constituição do narcisismo. Ao mesmo tempo, o sentimento de insuficiência corporal da criança diante da perfeição imaginária há de produzir uma divisão imediata e fundamental para que esse serzinho se transforme em um sujeito: o "eu ideal" refletido no espelho não se confunde com a experiência subjetiva. Esse ideal imaginário, que é, mas também não é o bebê, torna-se a meta narcísica a ser perseguida pelo sujeito, para o resto da vida.

$\mathrm{Na}$ falta de conseguirmos reconquistar a identidade com a perfeição perdida (que a partir de agora chamarei de nosso "eu ideal"), passaremos o resto da vida a tentar conquistar, pela identificação com características das pessoas que amamos, atributos de valor que restaurem o narcisismo primário - para sempre perdido - e nos permitam uma nova modalidade de amor próprio a que Freud chamou narcisismo secundário. A substituição do "eu ideal" pelo conjunto dos "ideais do eu" é uma passagem fundamental, progressista, no desenvolvimento do sujeito e de seus atributos, capacidades, talentos, valores. Em geral, a identificação com traços dos pais e de outras pessoas amadas participa da constituição desses ideais.

E o que fazer com a plenitude perdida? Como é possível, para nós que inauguramos a entrada no mundo dos "outros" marcados pela plenitude do "ser", nos conformarmos com nossa "falta a ser"? Nada. E tudo. Nada, porque não nos é dado o poder de reverter a operação que nos separou do outro e nos tornou incompletos. A falta, para nós humanos, é a melhor das opções: pois a não separação, ou a impossibilidade de simbolizar a separação, caracteriza a psicose - que é, no mínimo, um destino subjetivo mais árduo e mais solitário. Não trato dela aqui porque minha experiência clínica com a psicose é insuficiente.

Mas se não temos nada a fazer com nossa falta a ser, somos marcados, desde o inconsciente, pelo desejo de recuperar a plenitude perdida, ou seja, para nos tornarmos novamente o objeto que completa o outro. Em meu livro Sobre ética e psicanálise propus que considerássemos o neurótico como um escravo à procura de um mestre. De maneiras diferentes, tanto o/a obsessivo/a quanto o/a histérico/a passam a vida a se oferecer, ou a oferecer seus sintomas, a qualquer um que possa ocupar o lugar do outro - este que um dia foi ocupado pela mãe.

Faço uma pequena digressão para explicar que, na terminologia lacaniana, o outro (também chamado "grande outro") é a designação do campo simbólico. Outro é o 
campo dos significantes, o campo simbólico, indissociável da condição humana. Porém, uma vez que o infans é, via de regra, introduzido no campo simbólico pela mãe - os cuidados maternos são a primeira forma de linguagem por meio da qual o corpo deixa de ser meramente biológico e se insere na cultura - a poderosa mãe se torna a primeira “encarnação” psíquica do outro.

\section{A Utopia e o Desejo}

Essas observações a respeito do outro, como marcas que fundam o inconsciente, conduzem-nos à questão da neurose e à polêmica sobre a cura em psicanálise. A cura em psicanálise seria uma utopia? Ou o indivíduo que se diz curado representa a paródia reducionista do fim da travessia de seu processo do desejo?

Mesmo o pessimismo freudiano a respeito da felicidade humana deixa uma porta aberta para se conceber a cura em análise. Para realizar essa passagem, devo continuar a percorrer o caminho teórico que começa na emergência do sujeito, a partir da perda de sua completude inaugural (fusão com o "outro" materno), para chegar à constituição da fantasia (também dita fantasma) organizadora da estrutura neurótica.

Retomo nosso percurso. Para a psicanálise freudiana, a perda necessária da completude mãe-infans é condição da emergência do sujeito, incompleto por definição. Dessa operação de separação fica um resto, que, em verdade, é tudo: esse resto é o desejo, que há de mover o sujeito pela vida afora.

A fantasia fundamental do neurótico ${ }^{6}$ (que a psicanálise lacaniana denomina de fantasma, a fim de diferenciá-la da profusão de fantasias secundárias, produzidas ao longo da vida) é uma estrutura simbólica que sustenta o lugar em que o sujeito se coloca diante do outro, animado pela esperança de voltar a ser seu objeto de satisfação. Não é tão complicado quanto parece. Digamos que o neurótico é aquele que passa a vida inventando senhores a quem servir, na esperança de ser amado por algum deles e, assim, recuperar a plenitude perdida. Nessa perspectiva, podemos conceber o neurótico como um escravo em potencial, constantemente em busca de um mestre.

Parece que estamos falando de um sujeito bonzinho, não é? Submisso, obediente, etcétera e tal. Pode até ser assim, a depender do sintoma de cada um. Mas o propósito último da servidão voluntária do neurótico é descaradamente “fora da lei”. O que ele
6 Ser neurótico é ruim, não é? Mas ainda é nossa melhor opção. As outras duas seriam a perversão e a psicose. 
7 Não a perda do pênis ou de algum outro atributo corporal valioso, e, sim, a separação da totalidade que faz de todos nós seres incompletos - mas que, a partir daí, podemos nos tornar potentes, imaginativos, desejantes.

pretende, com seu sintoma (mas não felizmente consegue obter, a não ser na fantasia) é reverter o efeito da lei que introduziu a castração simbólica e recuperar uma plenitude perdida. Como essa reversão é impossível - e se fosse possível seria pior, pois lançaria o sujeito na psicose - o neurótico está condenado a repetir - por meio de seus sintomas, de seus fracassos, de suas frustrações amorosas - tentativas fracassadas de recuperar a perfeição narcísica.

A cura em psicanálise não configura uma utopia, se tomarmos esse termo no sentido de uma situação ideal, prefigurada pela imaginação, que pode ser atingida ou construída em um futuro sonhado. Ao falarmos da cura como uma utopia, referimo-nos à mudança de posição do sujeito na fantasia a partir da qual ele se oferece ao outro. É imprescindível que essa saída permita ao sujeito continuar a viver sob a lei que o estruturou desde o início, mas livre da submissão aos tais “mestres”, que o neurótico elege para oferecer seu sintoma em troca de amor e reconhecimento. Essa mudança de posição é utópica, no sentido literal da palavra: o processo psicanalítico abre a possibilidade do encontro do sujeito com um não lugar, lugar que ainda não é, mas que passará a existir no momento em que o analisando se desprender do lugar fantasmático submetido ao desejo do outro e se dispuser a criar, considerando seu próprio desejo, novos lugares por onde a libido inesgotável possa circular. Ela implica que o sujeito se deixe guiar pela negatividade do desejo que o estruturou e que não tem objeto fixo, nem no amor, muito menos no mundo dos bens de consumo, que o satisfaça, pois, como vimos, o objeto perdido que causa o desejo é o próprio sujeito, que perdeu a fusão primordial com o "outro" materno.

Não é grande coisa esse tal desejo. É a cenoura na frente do burro. O neurótico (eu, você...) nunca alcança a cenoura - que aliás não é nem cenoura, nem coisa nenhuma, é simplesmente a nostalgia inconsciente de um gozo perdido, o que não impede que façamos nosso caminho pela vida atrás dela, sem perceber que não é a cenoura que o conduz: é seu “desejo de cenoura” que inventa o percurso.

Qual o problema, então, de seguirmos com nossos sintomas perseguindo a totalidade impossível? Primeiro, em razão do estreitamento de nossa perspectiva existencial. A insistência em reverter a castração (pois é disso que se trata), em vez de abrir horizontes, conduz à repetição. Segundo, porque existe um problema ético na neurose. A servidão, ao contrário do que possa parecer, não é ética: aquele que obedece, ainda que 
de forma inconsciente, tende a não se responsabilizar pelas consequências de seus atos e não assumir algumas de suas escolhas. É sempre em nome do "bem” que o neurótico acredita agir. O pai excessivamente severo, a mãe sacrificada que deixa os filhos em permanente dívida para com seu amor, o marido controlador, a esposa manipuladora - todos eles se queixam ao analista o quanto são incompreendidos apesar de suas excelentes intenções. Lembrem-se de que o "outro" primordial já deixou de existir, no horizonte do sujeito. Então ele elege vários outros, seus semelhantes, aqueles a quem mais ama, para oferecer seu sintoma. O amor é lindo - mas é em nome dele que praticamos, muitas vezes sem nos dar conta, certas atrocidades. "Quando amo, dou o pior de mim”, disse-me com ironia um analisando, quando já era capaz de criticar sua alienação.

A travessia de uma análise exige coragem por parte do analisando. O próprio fato de procurar um analista, ciente de que vai receber uma série de "más notícias" a confrontar suas ilusões narcisistas, já é um ato de coragem. “O inconsciente é sempre má notícia”, teria dito Roman Polansky. Faz sentido: se fosse bom, não seria recalcado. Como resumir os termos dessa travessia a que chamamos processo analítico? Digamos que ela se dá desde uma estrutura aprisionante, em que o neurótico está sempre diante do outro a perguntar "o que desejas de mim"? - em direção a um outro lugar (subjetivo) onde, liberto da servidão voluntária, ele possa se indagar “qual desejo me move"? Nesse novo lugar, ele estará mais desamparado, mais sozinho. E ao mesmo tempo, mais livre. Ora: o desamparo é parte fundamental da condição humana. Só o fato de habitarmos o reino da linguagem, e não algum habitat ao qual a espécie já estaria adaptada há milênios, condena-nos ao desamparo. Só a linguagem, esse instrumento precioso e imperfeito - com suas imperfeições e imprecisões, sua distância em relação à "coisa" - oferece-nos o amparo incompleto da comunicação com o semelhante. Aliás, é por isso mesmo que a psicanálise é um processo de cura por meio da palavra: ela, a palavra, é a melhor ferramenta de que dispomos para lidar com o desamparo, para tocar o outro e nos aproximar dele.

A cura em psicanálise é uma utopia porque o lugar que ela almeja alcançar não está contido, de saída, nos termos da "dialética do senhor e do escravo" que move a neurose ${ }^{8}$. A cura, para quem se atreve a levar uma análise até o fim, produz-se pelo que chamamos de "atravessamento" do fantasma. Esse percurso vai desde a servidão voluntária com a qual o neurótico busca remendar a falta-a-ser até a aceitação da condição

8 Trabalhei mais detalhadamente esse aspecto em meu livro Sobre ética e psicanálise. São Paulo: Companhia das Letras, 2001. 
faltante e desejante que não é perfeita - mas é o melhor que podemos fazer de nossas vidas. Dito de outro modo, a análise é a longa travessia, desde o lugar aparentemente seguro de onde o neurótico se oferece como escravo a seu “mestre” inconsciente até um lugar ainda desabitado, que ele próprio vai construir na medida em que constitui objetos para sua satisfação. A satisfação do desejo nunca há de ser total; para o humano, só há duas experiências de totalidade: o útero e a morte.

O desejo se satisfaz precariamente em objetos parciais - entender isso é fundamental para nossas escolhas de destino. Porque o "objeto do desejo" não está adiante de nós. Está inscrito no inconsciente. É um objeto perdido, é o próprio sujeito na posição perdida de objeto do outro. Assim, os lacanianos costumam chamá-lo de objetocausa do desejo. Que objeto é esse? Paradoxalmente (e tenho que admitir que, muito mais que Freud, os analistas lacanianos adoram um paradoxo) o objeto-causa do desejo é o próprio sujeito que perdeu seu lugar junto ao outro. Um objeto vazio, portanto. Perdido desde a origem.

Não é tão ruim como parece. Se o desejo fosse desejo de algo, uma vez conquistado esse algo, deixaríamos de desejar. Não no sentido budista, de aceitar o vazio, mas no sentido do conformismo e da apatia depressivos. A utopia da cura em psicanálise aponta para a perspectiva de se tomar o vazio como causa do desejo, e assim deixar de apostar na submissão voluntária - ou no consumo, o que, por vezes, é outra versão da mesma coisa - como garantia de felicidade.

A psicanálise visa propiciar que o sujeito se desloque de um lugar ideal, e por isso mesmo "morto", em direção a outro, vivo e ainda vazio: pronto para ser percorrido pelo movimento incessante do desejo.

Em outras palavras, trata-se de trocar o tal "projeto reto de felicidade" (na expressão de Reinaldo Moraes) pela "prova dos nove” da alegria (na expressão de Oswald de Andrade). Nisso consiste a utopia da cura em psicanálise. 


\section{Referências}

FREUD, Sigmund. "Introdução ao narcisismo" (I9I4) Tradução Paulo César de Souza. In: Obras Completas, v. I2. São Paulo: Companhia das Letras, 20ı, p. I3-50.

GOLDENBERG, Ricardo. No círculo cínico ou: caro Lacan, por que negar a psicanálise aos canalhas? Rio de Janeiro: Relume Dumará, 2002.

KEHL, Maria Rita. Sobre ética e psicanálise. São Paulo: Companhia das Letras, $200 \mathrm{I}$.

LACAN, Jacques. "O estádio do espelho constitutivo da função do eu (Je)". Tradução para o espanhol de Tomás Segovia. In: Escritos II. México: Siglo Veitiuno Editores, I949, p. 86-93.

MORETTI, Franco. O burguês (20I0). Tradução de Alexandre Morales. São Paulo: Companhia das Letras, 2014 .

TOURNIER, Michel. Sexta feira ou os limbos do pacífico. Tradução de Fernanda Botelho. 3. ed. Rio de Janeiro: Bertrand Brasil, 200I. 